\title{
Current knowledge concerning optimum nutritional status of riboflavin, niacin and pyridoxine
}

\author{
Hilary J. Powers \\ Division of Child Health, University of Sheffield, Sheffield Children's Hospital, Western Bank, Sheffield S10 2TH, UK
}

\begin{abstract}
The term 'optimum nutrition' has evolved from a perceived need to base recommendations for nutrient intakes firmly in the context of function. It follows that 'optimum nutritional status' for individual nutrients should be defined in terms of biochemical or physiological markers having some functional value but also showing an appropriate relationship to nutrient intake. The present short review considers the current position regarding such markers for riboflavin, pyridoxine and niacin. It is concluded that whilst there are several biochemical measures which respond to changes in intake of each of these vitamins, no single measure is wholly satisfactory as a marker of optimum status.
\end{abstract}

Riboflavin status: Niacin status: Pyridoxine status: Markers of nutrient status

The objective is to consider how best to express optimum nutritional status in terms of biochemical or physiological markers, having, if possible, some functional meaning.

The questions that need to be addressed for each vitamin are:

(1) what are the current biochemical and/or physiological markers of nutrient status?

(2) is there a well-defined relationship between the marker and nutrient intake?

(3) to what extent can the biochemical marker be said to reflect some specific function in a target tissue?

(4) are there any promising developments that may help our search for functional markers for these vitamins?

\section{Riboflavin \\ What are the current biochemical and/or physiological markers of nutrient status?}

This vitamin is consumed in the diet as free riboflavin and two phosphorylated forms, FMN and FAD. Absorption occurs as riboflavin, followed by intracellular phosphorylation in the enterocytes. Phosphorylation and dephosphorylation are features of intracellular metabolism, and all three forms are found intracellularly. The most common vitamer in tissues and in the circulation is FAD. The tissue riboflavin pool is probably best evaluated by measuring blood FAD by HPLC using fluorescence detection (Florida et al. 1985). An alternative approach, but with obvious practical limitations, is the measurement of urinary riboflavin, which is a simple reflection of an excess of current intake over tissue requirements (Zempleni et al. 1996). This latter approach has provided useful information regarding the relationship between riboflavin intake and tissue saturation (Horwitt, 1986), of value in early studies of requirements for this vitamin. The method generally preferred for the estimation of riboflavin status is the stimulation of FAD-dependent erythrocyte GSH reductase (EC 1.6.4.2) in vitro, which relies on an associated oxidation of NADPH which can be readily monitored spectrophotometrically (Bates et al. 1986). Results are expressed as an activation coefficient (EGRAC).

\section{Is there a known relationship between the marker and nutrient intake?}

Plasma or erythrocyte FAD. Reasonable correlations have been demonstrated between plasma or erythrocyte flavin concentrations and other biochemical markers of riboflavin status in human subjects, although there is relatively little information regarding the tissue response to graded intakes of riboflavin. Plasma and urine riboflavin concentrations increased progressively in low-birth-weight infants during 4 weeks of enteral feeding (Porcelli et al. 1996), and erythrocyte riboflavin concentrations are reported to increase as quickly as EGRAC in response to

\footnotetext{
Abbreviations: EGRAC, erythrocyte GSH reductase activation coefficient; NNPPRT, nicotinate-nucleotide: pyrophosphate phosphoribosyltransferase; PLP, pyridoxal phosphate.

Corresponding author: Dr Hilary J. Powers, fax + 44 (0)114 2755364, email H.J.Powers@ sheffield.ac.uk
} 
riboflavin supplementation (Beutler, 1969). A recent study of the pharmacokinetics of flavin uptake in human subjects indicated an upper limit of absorption from a single dose of $27 \mathrm{mg}$ and demonstrated relatively modest changes in plasma riboflavin or flavocoenzymes following oral administration (Zempleni et al. 1996).

Animal studies are supportive of a relationship between dietary riboflavin and tissue flavin concentrations (Williams et al. 1996a), but erythrocyte flavins have received little attention.

Urinary riboflavin. The earliest attempts to associate dietary riboflavin intake with a biochemical marker utilized the urinary excretion of riboflavin (Horwitt et al. 1950). Balance studies in human subjects show clearly that as riboflavin intake increases there is a progressive rise in urinary excretion of riboflavin, which increases sharply at intakes of approximately $1.0 \mathrm{mg} / \mathrm{d}$ (Horwitt, 1986). This intake has been interpreted as reflecting tissue saturation. Although this approach has practical limitations for large population studies, because it provides information concerning tissue 'stores', it can arguably be useful as a marker of optimum nutritional status. This approach is less useful as a marker of riboflavin status at lower intakes.

Erythrocyte GSH reductase activation coefficient. Numerous studies have demonstrated a relationship between riboflavin intake and the extent to which erythrocyte GSH reductase can be stimulated by FAD in vitro (Bates et al. 1982, 1989; Boisvert et al. 1993). EGRAC is most sensitive to changes in riboflavin intake up to levels of intake approaching tissue saturation of this vitamin (about $1.0 \mathrm{mg} / \mathrm{d}$ on the basis of urinary excretion studies). However, some studies have highlighted differences in the relationship between intake and EGRAC values among different population groups (Bates et al. 1982; Belko et al. 1982). The measurement can broadly discriminate between levels of intake observed in an apparently-healthy population. Further increases in intake elicit no further fall in EGRAC, which limits its usefulness as a potential marker for optimum nutritional status.

\section{To what extent can the biochemical marker be said to reflect some specific function?}

Although EGRAC is sometimes referred to as a functional test of riboflavin status, it does not fulfill the most rigorous definition of this term. Over a broad range of EGRAC values in human subjects there is no well characterized change in any physiological function, or, indeed, altered flux through a metabolic pathway. Effects on work performance, neuromuscular coordination, and the handling of $\mathrm{Fe}$ have been observed in human subjects with EGRAC values of 1.7 and higher, and there is an element of riboflavin responsiveness of these variables, supportive of a causeeffect relationship (Bates et al. 1982, 1994; Prasad et al. 1990; Fairweather-Tait et al. 1992). Studies in animals confirm a dose-response relationship between riboflavin intake, EGRAC value and Fe handling (Powers et al. 1991) and have also identified impaired fatty acid oxidation, which is exacerbated by starvation-induced flux through fatty acid oxidation pathways (Bates, 1990; White, 1996) in animals fed on diets low in riboflavin. EGRAC values were not always reported, but the nature of the dietary restriction is strongly suggestive of severe deficiency. So far, attempts to reproduce effects of low riboflavin intakes on fatty acid oxidation in human subjects have not been successful (Bates et al. 1991). Dietary riboflavin restriction around weaning disturbs normal gastrointestinal development in rats (Powers, 1995; Williams et al. 1996b; Yates \& Powers, 1999); there may be a human corollary which could explain effects of dietary riboflavin restriction on growth.

In the UK population the evidence is that the elderly remain vulnerable to poor riboflavin status, expressed biochemically (Bailey et al. 1997). Of particular relevance to this group of the population may be the relationship that has been reported in several studies between dietary riboflavin, riboflavin status and lens opacity (Leske et al. 1995).

\section{Current developments}

A method has been proposed for the measurement of plasma riboflavin by titration of plasma against riboflavin-binding apoprotein; it is not yet clear whether this approach will offer any particular advantage over current methods of assessment (Kodentsova et al. 1995).

Thus, although low intakes of riboflavin will disturb a number of distinct physiological or biochemical processes, the effects are not sufficiently sensitive to riboflavin intake to be useful as functional markers of status. However, they may be useful to interpret EGRAC values.

\section{Niacin \\ What are the current biochemical and/or physiological markers of nutrient status?}

Niacin is a generic term for nicotinic acid and nicotinamide, both of which are substrates for the synthesis of nicotinamide nucleotide coenzymes, NAD and the phosphorylated derivative NADP. The vitamin is found in the tissues predominantly as the nicotinamide nucleotides. Biochemical assessment of niacin status is complicated by the fact that tryptophan is a precursor of niacin, and the availability of this amino acid will influence dietary niacin requirements. The concentration of erythrocyte and plasma NAD and NADP, and the urinary excretion of niacin metabolites have been explored as markers of niacin status, with variable results (Vivian et al. 1958; Nakagawa et al. 1969; Srikantia et al. 1986). More recently, the activity of nicotinatenucleotide: pyrophosphate phosphoribosyltransferase (EC 2.4.2.11; NNPPRT) in erythrocytes has received attention (Fu et al. 1989).

\section{Is there a known relationship between the marker and nutrient intake?}

Erythrocyte nucleotides. Fu et al. (1959) have shown very clearly that the erythrocyte concentration of NAD is sensitive to relatively short-term changes in niacin intake in young men. NADP on the other hand showed no significant response to differences in niacin intake over the range of 6.1-32 niacin equivalents. This relative insensitivity of erythrocyte NADP to niacin intake has also been reported in 
other studies in human subjects (Gross et al. 1960). NAD : NADP in erythrocytes or whole blood may be a useful variable when there are disturbances to haemoglobin synthesis or erythrocyte production. If total pyridine nucleotides in blood are measured it is to be expected that concentrations would fall as niacin intakes fall, although this decrease would be due almost entirely to changes in NAD.

Erythrocyte nicotinate-nucleotide: pyrophosphate phosphoribosyltransferase activity. The activity of NNPPRT in erythrocytes has been explored as a potential marker of niacin status. This enzyme catalyses the conversion of nicotinic acid to nicotinic mononucleotide. Although enzyme activity has been shown to increase in response to niacin depletion in pigs (Arienti et al. 1982), such an effect was not seen in rats (Shibata \& Matsuo, 1989), and activity was not found to be responsive to changes in niacin intakes in human subjects over a short period (Gross et al. 1960).

Urinary metabolites. In an experimental situation the $24 \mathrm{~h}$ urinary excretion of $\mathrm{N}^{\prime}$ methylnicotinamide, which is the main urinary metabolite of this vitamin, is seen to closely mirror changes in the dietary intake of niacin (Sauberlich, 1984). The lack of any apparent lag stage between changes in intake and changes in urinary excretion of this metabolite suggests that the latter may not be a sensitive reflection of tissue levels. Other metabolites of niacin are excreted in the urine, and a few studies have explored their relationship with niacin intakes. Two such metabolites are $\mathrm{N}^{\prime}$ methyl-2-pyridone-5-carboxamide and $\mathrm{N}^{\prime}$ methyl-4-pyridone-3-carboxamide. The correlation between niacin intakes in subjects on a self-selected diet and the urinary excretion of these two metabolites, expressed either as creatinine-corrected concentration or $24 \mathrm{~h}$ excretion, was similar for these two metabolites and better than that for $\mathrm{N}^{\prime}$ methylnicotinamide (Shibata \& Matsuo, 1989). There have been significant developments in the analytical methods available for measuring these urinary metabolites, which makes them especially attractive as markers of niacin status.

\section{To what extent can the biochemical marker be said to reflect some specific function?}

In the absence of functional variables specifically responsive to niacin intake, niacin status is currently synonymous with the concentration of the vitamin or metabolites in the plasma or erythrocyte or urine. There has been some interest recently in the possibility that low intakes of niacin equivalents may limit DNA repair following oxidative damage, through an effect mediated by NAD-dependent poly(ADP-ribosyl)ation (Rawling et al. 1996). This finding may have implications for carcinogenesis, and for this reason could attract future attention.

\section{Pyridoxine}

What are the current biochemical and/or physiological markers of nutrient status?

The term vitamin $\mathrm{B}_{6}$ encompasses three pyridines: pyridoxine (also called pyridoxol), pyridoxal and pyridoxamine, and their 5'-phosphorylated derivatives. The main form of the vitamin is pyridoxal phosphate (PLP) which once formed intracellularly is bound to enzymes for which it has cofactor activity. PLP is also the main extracellular form of the vitamin, being transported in plasma bound to albumin. PLP which is not enzyme-bound is oxidized to pyridoxic acid, which is excreted in the urine.

Widely-used techniques in current use for evaluating vitamin $\mathrm{B}_{6}$ status include the measurement of circulating PLP (Lumeng et al. 1978), urinary pyridoxic acid (Brown et al. 1975; Leklem, 1990), and the activation coefficient for the erythrocyte enzyme aspartate aminotransferase (EC 2.6.1.1; Brown et al. 1975; Fidanza, 1991).

\section{Is there a known relationship between the marker and nutrient intake?}

Plasma pyridoxal phosphate. Studies in weanling rats have shown that plasma PLP levels increase progressively with increasing intake of vitamin $\mathrm{B}_{6}$, in a similar fashion to muscle, which represents the largest site of tissue vitamin $\mathrm{B}_{6}$ (Lumeng et al. 1978). In contrast, other tissues appear to be saturable with PLP. In another rat study (Takami et al. 1968) plasma PLP was closely correlated with muscle glycogen phosphorylase (EC 2.4.1.1), which lends some functional significance to the measurement of the plasma vitamer.

Other studies in human subjects and animals are supportive of PLP in plasma as having diagnostic value for vitamin $\mathrm{B}_{6}$ status (Brown et al. 1975; Sampson \& O'Connor, 1989). In rats, plasma levels of PLP are more responsive to dietary vitamin $\mathrm{B}_{6}$ depletion than tissue levels, except for erythrocyte PLP, which also responds quickly to depletion. Plasma PLP levels achieved in adults at intakes of vitamin $\mathrm{B}_{6}$ between 0.8 and $10 \mathrm{mg} / \mathrm{d}$ give a reasonably consistent picture: plasma PLP of above $25 \mathrm{nmol} / \mathrm{l}$ is achieved at intakes greater than $1.0 \mathrm{mg} / \mathrm{d}$. When intakes rise to $10 \mathrm{mg} / \mathrm{d}$ plasma PLP rises to $200 \mathrm{nmol} / \mathrm{l}$ (Leklem, 1990).

The question is: are there any measurable benefits associated with this higher circulating level, and are there functional limitations imposed by levels less than $25 \mathrm{nmol} / \mathrm{l}$ ?

Urinary 4-pyridoxic acid. The amount of 4-pyridoxic acid excreted in the urine daily is a reflection of the irreversible oxidation of pyridoxal (from PLP) taking place in tissues. The daily excretion of 4-pyridoxic acid responds rapidly to dietary depletion and repletion (Brown et al. 1975; Leklem, 1990); in subjects among whom daily intakes do not fluctuate significantly, urinary excretion of 4-pyridoxic acid offers a useful indicator of the adequacy of vitamin $\mathrm{B}_{6}$ status. This marker is not sensitive to changes in vitamin intake when intake is low. Urinary 4-pyridoxic acid can be measured in a single fasting urine sample and expressed relative to urinary creatinine. However, current reference ranges say nothing about the functional significance of abnormally low excretion rates. There is current interest in the potential of plasma pyridoxic acid as a marker of vitamin $\mathrm{B}_{6}$ status.

Erythrocyte transaminase activity. The activities of erythrocyte transaminases are PLP-dependent; this measurement provides the basis for the indirect measure of vitamin $\mathrm{B}_{6}$ status, and at the same time is considered to offer a more functional approach to assessment than levels of circulating 
vitamers. The activity of either alanine (EC 2.6.1.2) or aspartate aminotransferase is measured in the absence and the presence of added PLP in an erythrocyte haemolysate; the resulting ratio of the activities in vitro is expressed as an activation coefficient, which increases with decreasing saturation of the endogenous enzyme. There does not seem to be a consensus regarding which of these two enzymes offers the more sensitive index of vitamin $\mathrm{B}_{6}$ status, or the speed with which the enzymes respond to changes in vitamin $\mathrm{B}_{6}$ intake (Brown et al. 1975; Fidanza, 1991).

\section{To what extent can the biochemical marker be said to reflect some specific function?}

Reference ranges can be determined for a population group under study, using particular assay conditions, but there has not been any convincing demonstration of consistent functional abnormality (in a target tissue) associated with enzyme activation values falling outside the reference range. In fact none of the methods currently in use for the assessment of vitamin $\mathrm{B}_{6}$ status satisfy the criteria for a functional marker in human subjects. Several authors call for the assessment of vitamin $\mathrm{B}_{6}$ status using more than one biochemical variable; there is reported to be some lack of concordance between certain indices, presumably because each may be influenced differently by factors other than vitamin B $_{6}$ intake (Leklem, 1990; Bender, 1993; KangYoon et al. 1995).

Some growth advantages of maternal supplements of vitamin $\mathrm{B}_{6}$ (pyridoxamine hydrochloride) were indicated in a small study of newborn infants (Kang-Yoon et al. 1995). In this study plasma and erythrocyte PLP concentrations and the activation coefficient for alanine aminotransferase correlated with calculated daily intakes of vitamin $\mathrm{B}_{6}$.

Other potential markers. Ornithine decarboxylase (EC 4.1.1.58) activity in selected tissues has received some attention as a potential functional indicator of vitamin $\mathrm{B}_{6}$ status, but so far there is no evidence that it is sensitive to vitamin $\mathrm{B}_{6}$ status (Sampson et al. 1995)

Homocysteine. There is current interest in the factors which determine plasma levels of homocysteine, as moderate elevations of this amino acid are associated with an increased risk of cardiovascular disease (Stampfer et al. 1992). As the metabolism of intracellular homocysteine is either by methylation (folate and vitamin $\mathrm{B}_{12}$-dependent) or by trans-sulfuration (vitamin $\mathrm{B}_{6}$-dependent), studies have focused on the homocysteine-lowering potential of these vitamins. The current impression is that folic acid status is a major dietary determinant of plasma total homocysteine, and the latter is amenable to folate supplementation (Dudman et al. 1993; Ubbink et al. 1994). Vitamin $\mathrm{B}_{6}$ status does not appear to have a strong independent effect on plasma homocysteine (Verhoef et al. 1996). Plasma total homocysteine does not appear therefore to offer a specific functional marker of vitamin $\mathrm{B}_{6}$ status.

\section{Conclusions}

There are several biochemical measures which respond to changes in dietary intake of riboflavin, niacin or pyridoxine, and each has some value as a marker of vitamin status.
However, markers for a single vitamin differ in terms of specificity and their sensitivity at low or high intakes. Thus, there is no single marker that is wholly satisfactory as a marker of a specific vitamin status. For a measure to be useful as a marker of optimum status it should be particularly sensitive to changes in vitamin intake at the upper end of the physiological intake range. Thus, urinary metabolites would be expected to have the greatest potential. Practical limitations, as well as interference with the relationship between intake and excretion by other factors, such as infection and exercise, have to be taken into account, and generally measurements of urinary metabolites have not been the methods of choice in recent studies of vitamin status. The so-called functional erythrocyte enzyme tests of riboflavin and pyridoxine status are not really satisfactory as markers of optimum nutrition as they are least sensitive at higher intakes. For riboflavin, at least, functional significance can be attached to enzyme activation coefficient values outside the normal range.

\section{References}

Arienti G, Simonetti MS \& Fidanza F (1982) The effect of niacin deprivation on nicotinic acid mononucleotide pyrophosphorylase of pig erythrocytes. International Journal of Vitamin and Nutrition Research 52, 142-147.

Bailey AL, Maisey S, Southon S, Wright AJA, Finglas PM \& Fulcher RA (1997) Relationships between micronutrient intake and biochemical indicators of nutrient adequacy in a 'free-living' elderly UK population. British Journal of Nutrition 77, 225-242.

Bates CJ (1990) Liberation of ${ }^{14} \mathrm{CO}_{2}$ from $\left[{ }^{14} \mathrm{C}\right]$ adipic acid and $\left[{ }^{12} \mathrm{C}\right]$ octanoic acid by adult rats during riboflavin deficiency and its reversal. British Journal of Nutrition 63, 553-562.

Bates CJ, Edwards G, Downes R \& Coward A (1991) ${ }^{13}$ C adipic acid as a probe of fatty acid oxidation in human subjects: feasability study and pilot trial of correction of riboflavin deficiency. Transactions of the Society of Tropical Medicine and Hygiene 81, 421-425.

Bates CJ, Evans PH, Allison G, Sonko BJ, Hoare S, Goodrich S \& Aspray T (1994) Biochemical indices and neuromuscular function tests in rural Gambian children given a riboflavin, or multivitamin plus iron, supplement. British Journal of Nutrition 72, 601-610.

Bates CJ, Powers HJ, Downes R, Brubacher D, Sutcliffe V \& Thurnhill A (1989) Riboflavin status of adolescent vs elderly Gambian subjects before and during supplementation. American Journal of Clinical Nutrition 50, 825-829.

Bates CJ, Powers HJ \& Prentice AM (1986) Measurement of riboflavin status by activation coefficient of erythrocyte glutathione reductase, and its automation with a Roche Cobas Bio centrifugal analyser. In Nutritional Status Assessment Methodology for Individuals and Groups, pp. 172-186 [F Fidanza, editor]. Perugia: Group of European Nutritionists.

Bates CJ, Prentice AM, Watkinson M, Morrell P, Sutcliffe BA, Foord FA \& Whitehead RG (1982) Riboflavin requirements of lactating Gambian women: a controlled supplementation trial. American Journal of Clinical Nutrition 35, 701-709.

Belko AZ, Obarzanek E, Kalkwarf HJ, Rotter MA, Bogusz S, Miller D, Haas JD \& Roe DA (1982) Effects of exercise on riboflavin requirements of young women. American Journal of Clinical Nutrition 37, 509-517.

Bender DA (1993) Lack of concordance between two biochemical indices of vitamin $\mathrm{B}_{6}$ nutritional status. Proceedings of the Nutrition Society 52, 315A. 
Beutler E (1969) Effect of flavin compounds on glutathione reductase activity: in vivo and in vitro studies. Journal of Clinical Investigation 48, 1957-1966.

Boisvert WA, Mendoza I, Castenada C, Portocarrer L, Solomons NW, Geshoff SN \& Russell RM (1993) Riboflavin requirement of healthy elderly humans and its relationship to macronutrient composition of the diet. Journal of Nutrition 123, 915-925.

Brown RR, Rose DP, Leklem JE, Linkswiler H \& Annand R (1975) Urinary 4-pyridoxic acid, plasma pyridoxal phosphate, and erythrocyte aminotransferase levels in oral contraceptive users receiving controlled intakes of vitamin $\mathrm{B}_{6}$. American Journal of Clinical Nutrition 28, 10-19.

Dudman NPB, Wilcken DEL, Wang J, Lynch JF, Macey D \& Lundberg P (1993) Disordered methionine/homocysteine metabolism in premature vascular disease: its occurrence, cofactor therapy and enzymology. Arteriosclerosis and Thrombosis 13, $1253-1260$.

Fairweather-Tait SJ, Powers HJ, Minski M, Whitehead J \& Downes R (1992) Riboflavin deficiency and iron absorption in adult Gambian men. Annals of Nutrition and Metabolism 36, 34-40.

Fidanza F (editor) (1991) Nutritional Status Assessment - A Manual for Population Studies, pp. 267-271. London: Chapman $\&$ Hall.

Florida A, Palmerini CA, Fini C, Pupita M \& Fidanza F (1985) High-performance liquid chromatographic analysis of FAD in whole blood. International Journal of Vitamin and Nutrition Research 55, 187-192.

Fu CS, Swendseid ME, Jacob RA \& McKee RW (1989) Biochemical markers of niacin status in young men: levels of erythrocyte niacin coenzymes and plasma tryptophan. Journal of Nutrition 119, 1949-1955.

Gross RT, Schroeder EA \& Gabrio RW (1960) Pyridine nucleotides in erythrocyte metabolism. Journal of Clinical Investigation $\mathbf{4 2 ,}$ 249-255.

Horwitt MK (1986) Interpretations of requirements for thiamin, riboflavin, niacin-tryptophan, and vitamin $\mathrm{E}$ plus comments on balance studies and vitamin $\mathrm{B}_{6}$. American Journal of Clinical Nutrition 44, 973-985.

Horwitt MK, Harvey CC, Hills OW \& Liebert E (1950) Correlation of urinary excretion of riboflavin with dietary intake and symptoms of ariboflavinosis. Journal of Nutrition $\mathbf{4 1}$, 247-264.

Kang-Yoon SA, Kirksey A, Giacola GP \& West KD (1995) Vitamin $\mathrm{B}_{6}$ adequacy in neonatal nutrition: associations with preterm delivery, type of feeding, and vitamin $\mathrm{B}_{6}$ supplementation. American Journal of Clinical Nutrition 62, 932-942.

Kodentsova VM, Vrzhesinskaya OA \& Spirichev VB (1995) Fluorometric riboflavin titration in plasma by riboflavin-binding apoprotein as a method for vitamin $\mathrm{B}_{2}$ status evaluation. Annals of Nutrition and Metabolism 39, 355-360.

Leklem JE (1990) Vitamin B $_{6}$ : a status report. Journal of Nutrition 120, 1503-1507.

Leske MC, Wu SY, Hyman L, Sperduto R, Underwood B, Chylac LT, Milton RC, Srivastava S \& Ansari N (1995) Lens Opacities Case Control Study Group. Archives of Ophthalmology 113, $1113-1118$

Lumeng L, Ryan MP \& Li TK (1978) Validation of the diagnostic value of plasma pyridoxal 5 phosphate measurements in vitamin $\mathrm{B}_{6}$ nutrition of the rat. Journal of Nutrition 108, 545-553.

Nakagawa L, Takahashi T, Suzuki T \& Masana Y (1969) Effect in man of the addition of tryptophan or niacin to the diet on the excretion of their metabolites. Journal of Nutrition 99, 325-330.

Porcelli PJ, Adcock EW, Delpaggio D, Swift LL \& Greene HL (1996) Plasma and urine riboflavin and pyridoxine concen- trations in enterally fed very-low-birth-weight neonates. Journal of Paediatric Gastroenterology and Nutrition 23, 141-146.

Powers HJ (1995) Riboflavin-iron interactions with particular emphasis on the gastrointestinal tract. Proceedings of the Nutrition Society 54, 509-517.

Powers HJ, Weaver LT, Austin S, Wright AJA \& Fairweather-Tait SJ (1991) Riboflavin deficiency in the rat: effects on iron utilization and loss. British Journal of Nutrition 65, 487-496.

Prasad PA, Bamji MS, Lakshmi AV \& Satyanarayama K (1990) Functional impact of riboflavin supplementation in urban school children. Nutrition Research 10, 275-282.

Rawling JM, Apsimon MM \& Kirkland JB (1996) Lung poly(ADPribose) and NAD+ concentrations during hyperoxia and niacin deficiency in the Fischer-344 rat. Free Radicals in Biology and Medicine 20, 865-871.

Sampson DA, Harrison SC, Clarke SD \& Yan X (1995) Dietary protein quality alters ornithine decarboxylase activity but not vitamin $\mathrm{B}_{6}$ nutritional status in rats. Journal of Nutrition $\mathbf{1 2 5}$, 2199-2207.

Sampson DA \& O'Connor DK (1989) Responses of $B_{6}$ vitamers in plasma erythrocytes and tissues to vitamin $\mathrm{B}_{6}$ depletion and repletion in the rat. Journal of Nutrition 19, 1940-1948.

Sauberlich HE (1984) Newer laboratory methods for assessing nutriture of selected B complex vitamins. Annual Review of Nutrition 4, 377-407.

Shibata K \& Matsuo H (1989) Correlation between niacin equivalent intake and urinary excretion of its metabolites, $\mathrm{N}^{\prime}$ methylnicotinamide, $\mathrm{N}^{\prime}$ methyl-2-pyridone-5-carboxamide and $\mathrm{N}^{\prime}$ methyl-4-pyridone-3-carboxamide in humans consuming a self-selected food. American Journal of Clinical Nutrition 50, 114-119.

Srikantia SG, Narasinga RBS, Raghuramulu N \& Gopalan C (1986) Pattern of nicotinamide nucleotides in the erythrocytes of pellagrins. American Journal of Clinical Nutrition 21, 13061309.

Stampfer MJ, Malinow R, Willet WC, Newcomer LM, Upson B, Ullmann D, Tishler PV \& Hennekens CH (1992) A prospective study of plasma homocysteine and risk of myocardial infarction in US physicians. Journal of the American Medical Association 268, 877-881.

Takami M, Fujioka M, Wada H \& Taguchi T (1968) Studies on pyridoxine deficiency in rats. Proceedings of the Society of Experimental Biology and Medicine 129, 110-117.

Ubbink JB, Vermaak WJH, van der Merwe A, Becker PJ, Delport R \& Potgieter HC (1994) Vitamin requirements for the treatment of hyperhomocysteinemia in humans. Journal of Nutrition 124, 1927-1933.

Verhoef P, Stampfer MJ, Buring JE, Gaziano JM, Allen RH, Stabler SP, Reynolds RD, Kok FJ, Hennekens CH \& Willett WC (1996) Homocysteine metabolism and risk of myocardial infarction: relation with vitamins $\mathrm{B}_{6}, \mathrm{~B}_{12}$ and folate. American Journal of Clinical Nutrition 143, 845-859.

Vivian VM, Chaloupka MM \& Reymolds MS (1958) Some aspects of tryptophan in human subjects. I. Nitrogen balances, blood pyridine nucleotides and urinary excretion of $\mathrm{N}^{\prime}$ methyl nicotinamide and $\mathrm{N}^{\prime}$ methyl-2-pyridone-5-carboxamide on a low niacin diet. Journal of Nutrition 66, 587-598.

White HB (1996) Sudden death of chicken embryos with hereditary riboflavin deficiency. Journal of Nutrition 126, Suppl. 4, 1303S1307S.

Williams EA, Rumsey RDE \& Powers HJ (1996a) An investigation into the reversibility of the morphological changes seen in the small intestine of riboflavin-deficient rats. Gut 39, 220-225.

Williams EA, Rumsey RDE \& Powers HJ (1996b) Cytokinetic and structural responses of the rat small intestine to riboflavin depletion. British Journal of Nutrition 75, 315-324. 
Yates CA \& Powers HJ (1999) Luminal riboflavin is essential for normal morphological development of the gastrointestinal tract. Proceedings of the Nutrition Society 58, 55A.
Zempleni J, Galloway JR \& McCormick DB (1996) Pharmacokinetics of orally and intravenously administered riboflavin in healthy humans. American Journal of Clinical Nutrition 63, 5466.

(C) Nutrition Society 1999 